\title{
Experimental Investigation on the Ice Accretion Effects of Airplane Compressor Cascade of Stator Blades on the Aerodynamic Coefficients
}

\author{
M. Ramezanizadeh ${ }^{1}$, S. M. H. Pouryoussefi ${ }^{1}$, M. Mirzaei $^{2 \dagger}$ and S. G. Pouryoussefi $^{2}$ \\ ${ }^{1}$ Air University of Shahid Sattari, Tehran, Iran \\ ${ }^{2}$ K.N.Toosi University of Technology, Center of Excellence for Design and Simulation of Space Systems, \\ Tehran, Iran
}

†Corresponding Author Email: mirzaei@kntu.ac.ir

(Received November 12, 2010; accepted January 14, 2012)

\begin{abstract}
In this paper the effects of ice accretion on the pressure distribution and the aerodynamic coefficients in a cascade of stator blades were experimentally investigated. Experiments were conducted on stage 67A type stator ControlledDiffusion blades, which represent the mid-span of the first stage of the stator for a high-bypass turbofan engine. The measurements were carried out over a range of cascade angle of attack from $20^{\circ}$ to $45^{\circ}$ at Reynolds number of 500000. Experimental blade surface pressure coefficient distribution, lift and drag force coefficients, and momentum coefficients for clean blades were compared with those of the iced blades and the effects of ice accretion on these parameters were discussed. It is observed that the ice accretion on the blades causes the formation of flow bubble on the pressure side, downstream of the leading edge. By increasing the angle of attack from $20^{\circ}$ to $35^{\circ}$, the bubble length decreases and the pressure coefficient increases inside the bubble region, constantly. In addition, for the iced blades the diffusion points at the suction side come closer to the trailing edge. In addition, it is found that by increasing the angle of attack up to $35^{\circ}$, the ice accretion has no significant effect on the lift coefficient but the drag coefficient increases comparing with the clean blades. More over at $40^{\circ}$ and $45^{\circ}$, by increasing the flow interference effects between the blades, the iced blades experience higher lift and lower drag in comparison with the clean ones.
\end{abstract}

Keywords: 67A cascade stator blades, Pressure distribution, Iced blade, Airplane engine compressor, Stall conditions.

\section{INTRODUCTION}

Inclement weather consideration play an important role in design, analysis, testing and operation of modern high bypass aircraft engines (Venkataramani et al. 2007). Since 1990 until 2005, about 240 air crashes have been reported due to the icing in daily flights, which 62 cases were reported as the turbofan engines power loss events. Generally, icing phenomenon occurs at altitudes higher than $22000 \mathrm{ft}$. in which there is a possibility for existence of super cooled liquid water (Mason et al. 2006). Icing creates circumstances in which the super cooled particles of water are accumulated on airframes, engines, propellers and etc. Such accumulation causes the flow disturbance. Mirzaei et al. (2009) performed a research using both experimental and numerical approaches on the effects of icing on aerodynamic parameters of NLF-0414 airfoil. It was found that the icing phenomenon on the aerodynamic surfaces such as airplane wing could decrease lift down to $30 \%$ and increase drag up to $40 \%$. While there are many researches done on the effects of icing on wings and airfoils, however, relatively less attention has been paid to the icing effects on the performance of engine inlets, although the effects can be hazardous to engines and aircraft. In particular, ice accretion on the aircraft engine inlet lip can alter the shape of the inlet lip and can cause serious degradation of the performance of an engine inlet (Jin and Taghavi 2008).

Ice accretion downstream the guide vanes could block the air inletting to the engine; this is a stalling circumstance and a serious degradation of the vanes performance. Ice accretion on the booster part of the inlet upstream the guide vanes will decrease the flow rate of inletting core flow and its acceleration. This may cause separation of ice particles and entering the engines, which can damage the mechanical parts downstream, or even stalling the engine or much worse 
may cause the engine powerloss during the flight (Mason et al. 2006 and Rasmussen et al. 2006). On the other hand, ice accretion on the first stage of the stator blades in aircraft engines which are located downstream of the guide vanes, has been recently an interesting subject for researchers. The mechanism of ice accretion on these blades and its aerodynamic and propulsion effects on the engine and the aircraft in general is the base point to investigate this phenomenon. Obtaining the flight certification in the icing condition needs various test flight, which is not only a costly process but also is dangerous. Therefore, it is necessary to simulate this phenomenon experimentally and numerically to provide a useful database and a comprehensive understanding of the effects of ice accretion.

The stator 67A blades which are of the controlled diffusion blades family have been designed by Sanger (1983). Compressor stage 67A was previously studied experimentally and numerically at turbomachinery lab of Naval Postgraduate School by Sanger and Shreeve (1986). Currently, the stage 67A blades are being used in airplane engine compressor blades analysis. These types of blades are used in the compressor first stage of some turbofan engines such as Rolls-Royce 884 Trent and General Electric's GE-90.

Experimental modeling of the shape and geometry of ice accretion especially in cascade on turbomachines has many points and complications. To investigate and analysis the aerodynamic effects of ice accretion, first the ice shape and geometry must be obtained. Since the circumstances of ice formation on the compressor stator blades are very hard to simulate and in flight conditions, these blades are located in the engines, access and having an estimation of the shape and geometry of the ice on the blades is very difficult. LEWICE is one of the comprehensive computer codes for simulation of the phenomenon of icing on airplane designed by NASA.

Ice shapes on airplane engine compressor stage 67A blades were simulated by Lee et al. (2006) at the University of Illinois. Moreover, Lee and Lath (2008) extend their work numerically using turbulence modeling by the method of RANS and using LEWICE code. Ice accretion on the blades and its thickness is found to be significantly sensitive to various factors such as droplet size; water contents, ambient temperature and integration time, which all are included in LEWICE code. On the other hand, it is found that the ice shape has weak sensitivity to the inlet flow incident angle and flow turbulence. Figure 1 compares three blades in icing accretion and its thickness simulated by LEWICE software (Lee et al. 2006). The blades are in the same conditions except in case (a), the size of droplets, in case (b), the integration time and in case (c), the temperature varies. Pouryoussefi et al. (2010) have experimentally surveyed aerodynamic coefficients of 67A stator stage blades. They obtained useful results about the stall condition for the clean blades. Science ice accretion can directly affect the stall conditions of the blades, an experimental study on icing phenomenon for these types of the blades is needed. In this study, the effects of ice accretion on the pressure coefficient distributions, drag, lift and moment coefficients were experimentally investigated on the stage 67A stator blades. The results of this investigation can provide useful perception of the effects of the ice accretion on the aerodynamic parameters and the performance of the stator blades.

\section{EXPERIMENTAL DETAILS}

The experiments were conducted in low-speed, opencircuit wind tunnel of aerospace engineering department, K.N. Toosi University of Technology. The wind tunnel test-section is $1.2 \mathrm{~m}$ wide, $1 \mathrm{~m}$ high and 3 $\mathrm{m}$ long. The maximum velocity in the test-section is 65 $\mathrm{m} / \mathrm{s}$. under uniform flow conditions, the longitudinal free-stream turbulence intensity is less than $0.2 \%$ and the velocity non-uniformity across the test section is $\pm 0.5 \%$.

In this study, the experiments were carried out on stage 67A stator blades. For this purpose, three iced blades were used to simulate the two dimensional flow over a cascade of iced stator blades. All of the blades were made of plexiglass which were cut with laser cuter device. The precision of the laser cuter device was $\pm 0.01 \mathrm{~mm}$ and the blade surfaces were finished by painting and polishing: $\operatorname{Ra}(\mu \mathrm{m})=0.05$. Two parallel plates were used at two sides of the cascade span to simulate the two dimensional flow. In addition, all the pressure coefficients distribution and aerodynamic coefficients measurements were performed on the middle blade which was situated between the two other blades. The errors in the spacing and in the alignment of the blades were within $\pm 0.01 c$, where $c$ is the chord length of the blades. For the iced cascade all of the dimensions were the same as the clean cascade whereas ice shape was attached to the blades. The experiments were carried out at Reynolds number of 500000 based on the chord length of a single blade and free stream velocity. Six angles of attack for cascade were investigated ranging from $20^{\circ}$ to $45^{\circ}$. Figure 2 shows a schematic view of the cascade of stator blades for clean and iced blades which explains the experimental set-up in the wind tunnel. Moreover, Table 1 illustrates the characteristics of the clean blades and cascade geometry.

The ice shape which was used in the present study was obtained on the 9 min ice accretion for angle of attack of $32.95^{\circ} \mathrm{deg}$ and for $20 \mu \mathrm{m}$ droplets at $-4 \mathrm{~F}^{\circ}$ with coupled method in LEWICE (Lee et al. 2006). Since, it is found that this type of icing in shape and size have weak sensitivity to the inflow attack angle variations and turbulence around the stage (Lee et al. 2006 and Lee and Loth 2008), ice shape was assumed constant in all angles of attack during the experiments. Figure 3 depicts an iced blade which has been formed in such circumstances. 


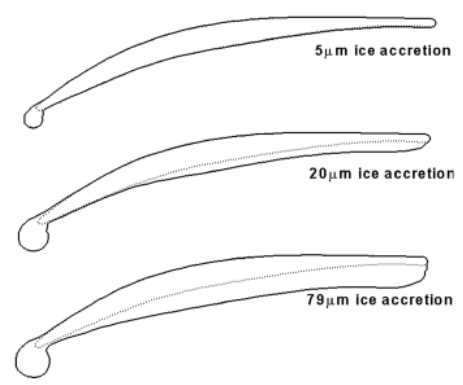

(a) (Lee et al. 2006)

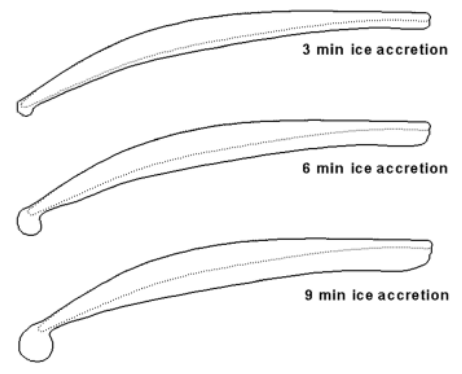

(b) (Lee et al. 2006)

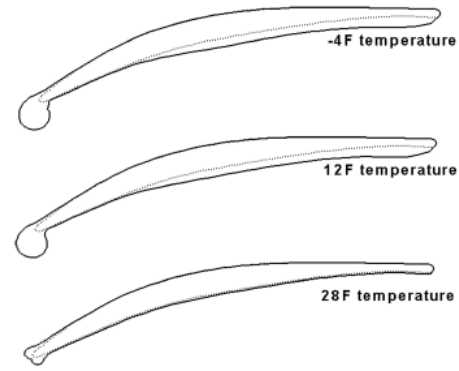

(c) (Lee et al. 2006)

Fig. 1. Ice accretion shapes: (a) for different droplet size; (b) at 3 min intervals; and (c) for different temperatures.

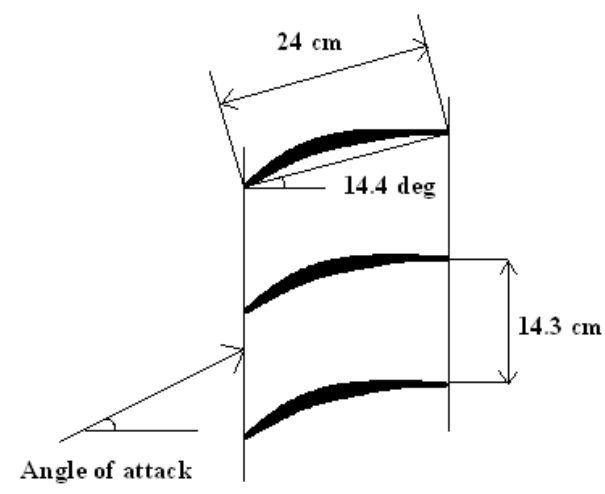

(a)

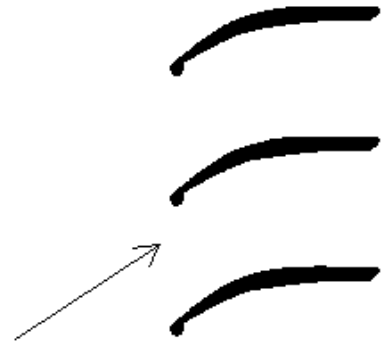

(b)

Fig. 2. Schematic view of the cascade of stator blades (experimental set-up in the wind tunnel):

(a) clean blades (Pouryoussefi et al. 2010); and (b) iced blades

Table 1 The characteristics of the clean blade and cascade geometry. (Stage 67A cascade stator blades)

\begin{tabular}{|lr|}
\hline Camber, deg & 41.09 \\
Max thickness, percent chord & 7.0 \\
Leading edge radius, percent chord & 0.9 \\
Trailing edge radius, percent chord & 1.26 \\
Solidity ratio (chord/pitch) & 1.67 \\
Stagger angle, deg & 14.4 \\
Blade aspect ratio & 2 \\
Chord length, cm & 24 \\
Blade spacing, cm & 14.3 \\
Span length, cm & 48 \\
\hline
\end{tabular}

To obtain the surface pressure distribution on the blade, forty pressure taps with inner diameter of $0.5 \mathrm{~mm}$ and outer diameter of $1.5 \mathrm{~mm}$ are provided (twenty on pressure side and twenty on suction side) in two parallel rows within $1.5 \mathrm{~cm}$ distance from each other around the middle blade mid-span in a zigzag manner circumferentially (for both clean and iced blades).

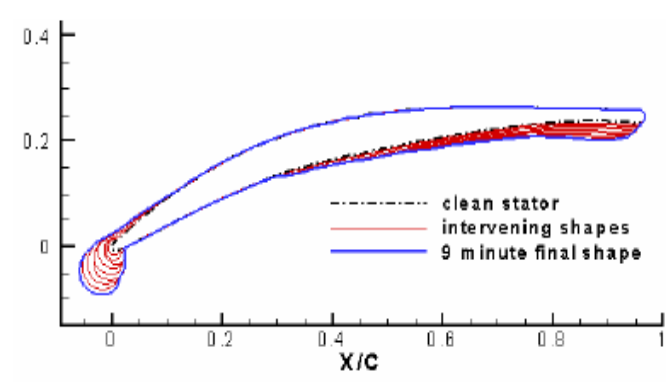

Fig. 3. The ice shape used in the present experiments (Lee et al. 2006) 
Figure 4 illustrates the pressure tap locations on the surfaces of the clean and iced blades.

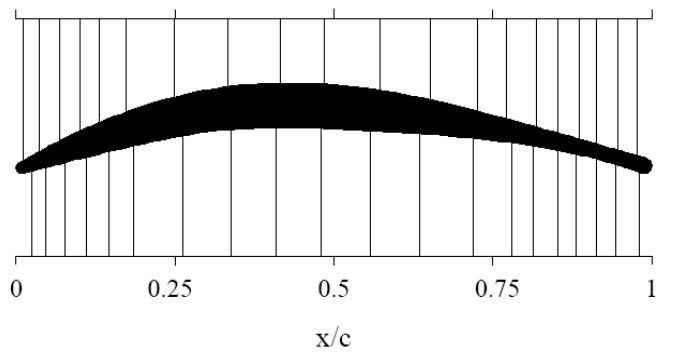

(a)

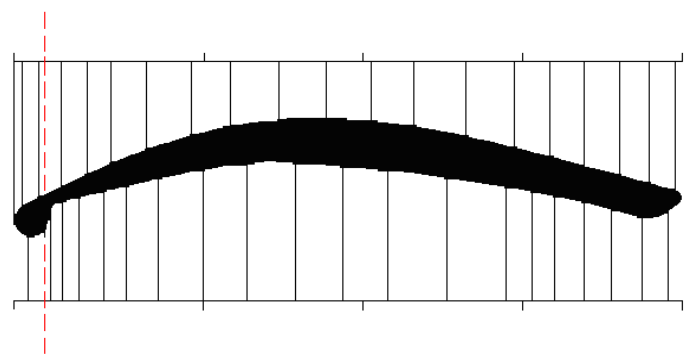

(b)

Fig. 4. The pressure taps locations on the surfaces of: (a) clean blade (Pouryoussefi et al. 2010); and (b) iced blade

The experiments were accomplished in six different angles of attack: $20^{\circ}, 25^{\circ}, 30^{\circ}, 35^{\circ}, 40^{\circ}$ and $45^{\circ}$. Since for changing the angle of attack, the whole stage of the cascade should rotate, but the test section walls are kept fixed, so we can claim that the inlet flow angle relative to the stage is almost the same as that of the outlet flow and they are parallel to the test section walls. During the experiments, reference flow conditions were measured with a Pitot-static tube and a micro-manometer. On the other hand, the measurement system of the surface pressure was consisted of pressure transducers (Honeywell-DC005NDC4), a National Instruments (NI) PCI-6224 16-bit A/D board with 32 analogue input channels, F.S.S (Farasanjesh) Pressure Field software and a personal computer.

The estimated measurement uncertainties of the pressure, lift, drag and moment coefficients are: $C_{P} \pm 0.01, C_{L} \pm 0.015, C_{D} \pm 0.02$ and $\mathrm{C}_{\mathrm{M}} \pm 0.015$, respectively (the mean aerodynamic coefficients have been measured by pressure distribution method). The pressure coefficient $C_{P}$, the lift coefficient $C_{L}$, the drag coefficient $C_{D}$ and the moment coefficient $C_{M}$ for the blades are defined as

$$
\begin{aligned}
& C_{P}=\left(P-P_{\infty}\right) /\left(0.5 \rho V_{\infty}{ }^{2}\right), C_{L}=L /\left(0.5 \rho V_{\infty}^{2} c\right), \\
& C_{D}=D /\left(0.5 \rho V_{\infty}^{2} c\right) \text { and } C_{M}=M /\left(0.5 \rho V_{\infty}^{2} c^{2}\right)
\end{aligned}
$$

respectively, where $P$ is the mean static pressure on the surface of the blade, $P_{\infty}$, the static pressure of the free-stream flow, $L$, the lift force, $D$, the drag force, $M$, the leading edge pitching moment, $c$, the chord length of the blades, $\rho$, the air density and $V_{\infty}$, the free-stream velocity.

\section{RESUlTS AND DiscuSSION}

As stated previously, for measuring the mean aerodynamic coefficients, the method of pressure distribution was applied using pressure distribution integration around the mid span of the clean and iced blades. Since the blades are high mean camber airfoils and are subjected to high angle of attack, the contribution of friction in drag coefficient is negligible. So, to obtain the drag coefficient, the numerical integration of pressure distribution on the blade surface was used.

To evaluate the validating of the wind tunnel performance and measurement tools, the results have been compared with those of Sanger and Shreeve (1986) in angle of attack of $20^{\circ}$ and nearly the same Reynolds number (shown in Fig. 5). A good agreement can be found between their results and those of the present study. There is only a small difference, which may be due to test conditions and instruments precision. Figures 6 to 11 show the pressure coefficient distributions for both clean and iced cascades. Lift, drag and moment coefficients variations for the clean and iced blades vs. angle of attack are shown in Figs. 12 to 14.

\subsection{Clean Blades}

It is observed that in $20^{\circ}$ at the suction side, the pressure coefficient decreases from the leading edge up to $x / c \approx 0.3$ and then gradually increases. The diffusion (divergence) point in the suction side can be found nearly at $x / c=0.3$ which is the peak of the pressure distribution curve on the suction side. At the pressure side, the pressure coefficient sharply increases from the leading edge up to $x / c \approx 0.4$ and then remains constant with some small fluctuations. On the suction side, the pressure coefficient distribution in $25^{\circ}$ approximately has a similar trend of $20^{\circ}$ case 


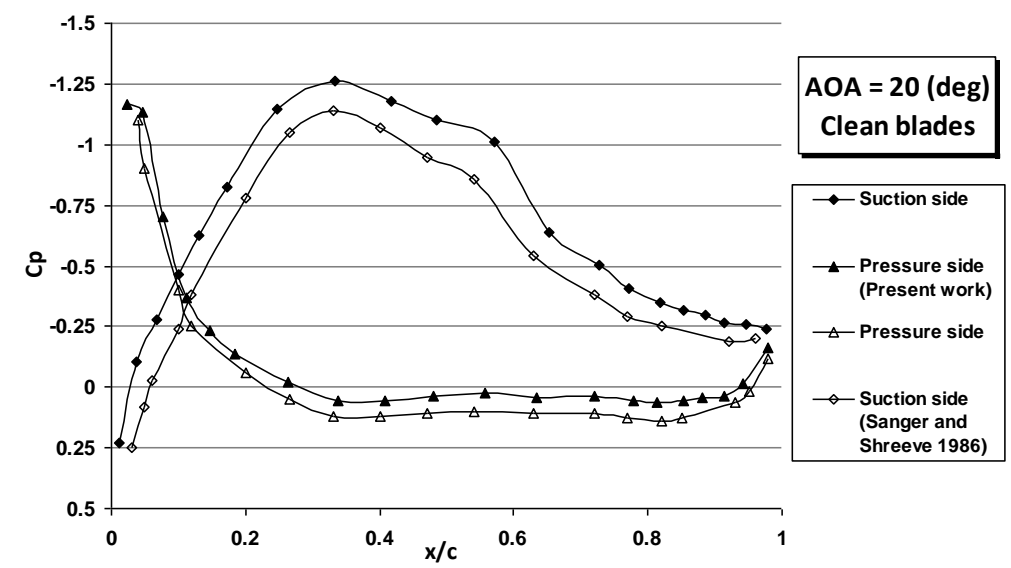

Fig. 5. Comparison of the pressure coefficient distribution with Singer and Shreeve (1986) experimental results

and it can be seen that, the diffusion point is around $x / c=0.3$. In $30^{\circ}$, due to the local suction at the leading edge of the suction side, a pick appears at $x / c \approx 0.05$. In $25^{\circ}$, the pressure coefficient significantly decreases around the leading edge, in comparison with $20^{\circ}$ at the suction side and at the pressure side. This causes an increase in difference between the pressure at the suction and the pressure side, by increasing the angle of attack. Such trend continues up to $35^{\circ}$, just before the aerodynamic stall of the clean blades. It is observed that in the range of angle of attack from $20^{\circ}$ to $35^{\circ}$, the pressure coefficient at the trailing edge arrives close to -0.25 . It is obvious that in $35^{\circ}$ in contrary to the lower angle of attack, at the suction side, the diffusion point approaches to the leading edge and the pressure coefficient decreases to -2.75 . As it is seen for the pressure distribution at the suction side in $35^{\circ}$, there is a negative constant pressure region from trailing edge to $x / c \approx 0.8$ which shows the occurrence of the separation phenomenon. The movement of the diffusion point at the suction side (which is corresponding to the flow separation at the trailing edge) causes reduction of the performance of cascade in $35^{\circ}$. The pressure distribution of the blades in $35^{\circ}$ has significant changed in comparison with those of the lower angles. These variations indicate approaching to the aerodynamic stall for the blades. By increasing the angle of attack, in $40^{\circ}$ and $45^{\circ}$, the separation point moves from $x / c=0.8$ to the leading edge and whole the suction surface is exposed to the separation and the pressure coefficient is almost constant. The pressure coefficient distributions for $40^{\circ}$ and $45^{\circ}$ are almost the same due to stall conditions. The different behavior of the pressure coefficient distribution at the pressure side in these two angles in comparison with the lower angles is due to increasing of the flow interference effect between the blades. Moreover, there is no significant separation region at the pressure side. There should be more experiments on the pressure distribution in angle of attack ranging from $35^{\circ}$ to $40^{\circ}$ to have more details about the flow separation region at the suction side.

Figures 12 to 14 illustrate the variations of lift, drag and moment coefficients for the clean and iced blades vs. angle of attack. According to the lift coefficient for the clean blades (Fig. 12), it has linear behavior from $20^{\circ}$ to $35^{\circ}$ and stall occurs after $35^{\circ}$. In angles from $40^{\circ}$ to $45^{\circ}$, the blade has completely stalled. On the other hand, the drag coefficient of the clean blades (Fig. 13) increases before the stall of the blade. An interesting trend of the drag coefficient occurs at angles between $30^{\circ}$ to $35^{\circ}$. In this range, the growth rate of the coefficient significantly decreases and this trend changes between $35^{\circ}$ and $40^{\circ}$ due to stall conditions. Moreover, the variation of moment coefficient (Fig. 14) in the range of $20^{\circ}$ to $30^{\circ}$ (before blade's stall) is linear but in the angles close to the stall and afterwards, its trend changes and fluctuates around -0.4. Basically, it can be concluded that the lift and drag behavior due to the angle of attack, is almost similar to those of the flow around a 2D airfoil (Mirzaei et al. 2009). Whereas, the different moment behavior in comparison with the 2D airfoil can be due to the severe flow interference between the blades at high angles of attack. More study should be done specially on the flow pattern to know the complicated behavior of the aerodynamic coefficients at angles close to the aerodynamic stall.

\subsection{Investigation of the Ice Accretion Effects}

According to the pressure distribution for the clean blades and iced ones (Figs. 6 to 11), it is observed that in $20^{\circ}$ for iced blades, at the suction side, the pressure coefficient decreases from the leading edge to 


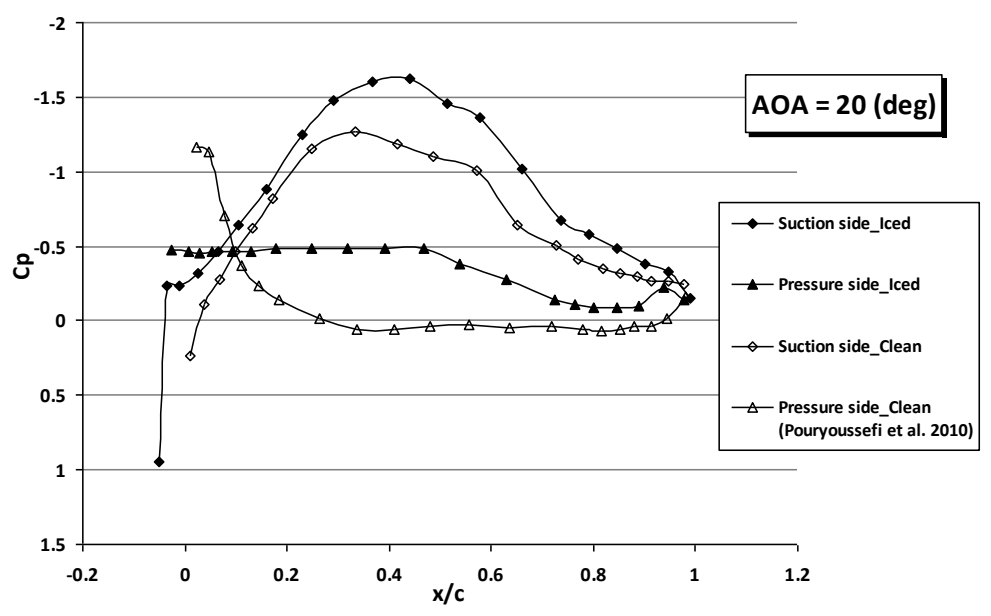

Fig. 6. The pressure coefficient distribution on the blade surface at $20^{\circ}$

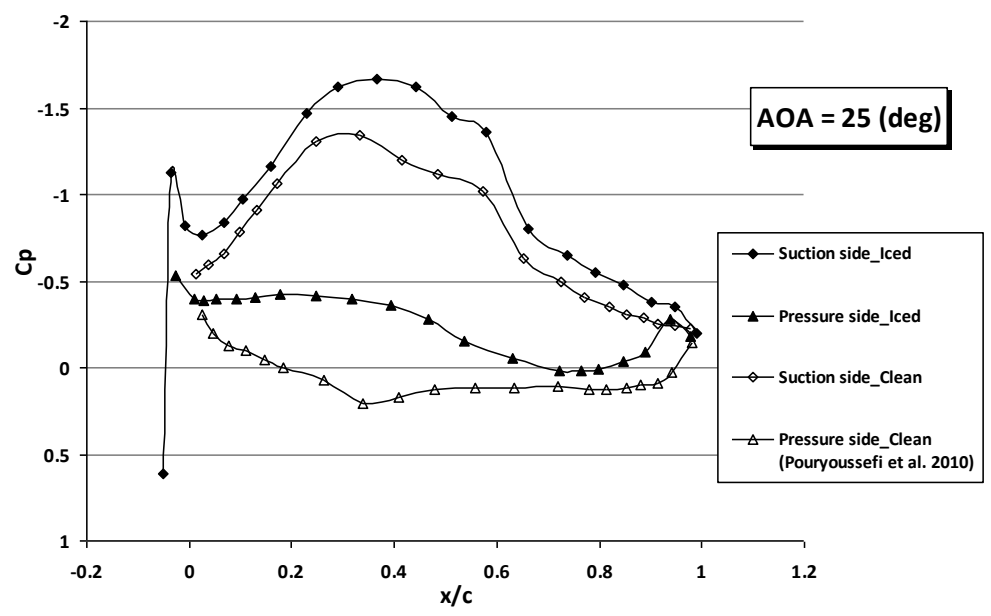

Fig. 7. The pressure coefficient distribution on the blade surface at $25^{\circ}$

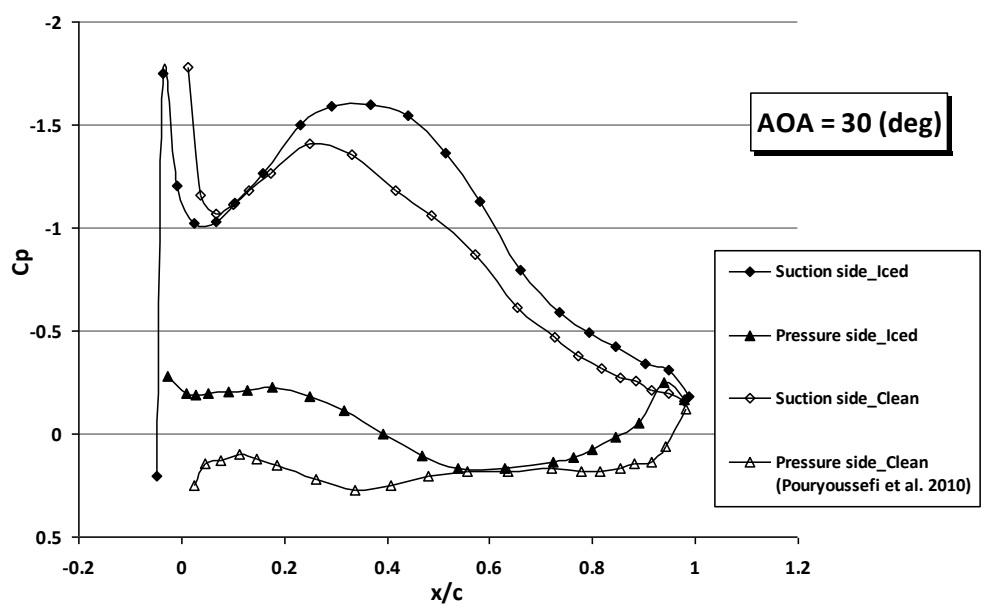

Fig. 8. The pressure coefficient distribution on the blade surface at $30^{\circ}$ 


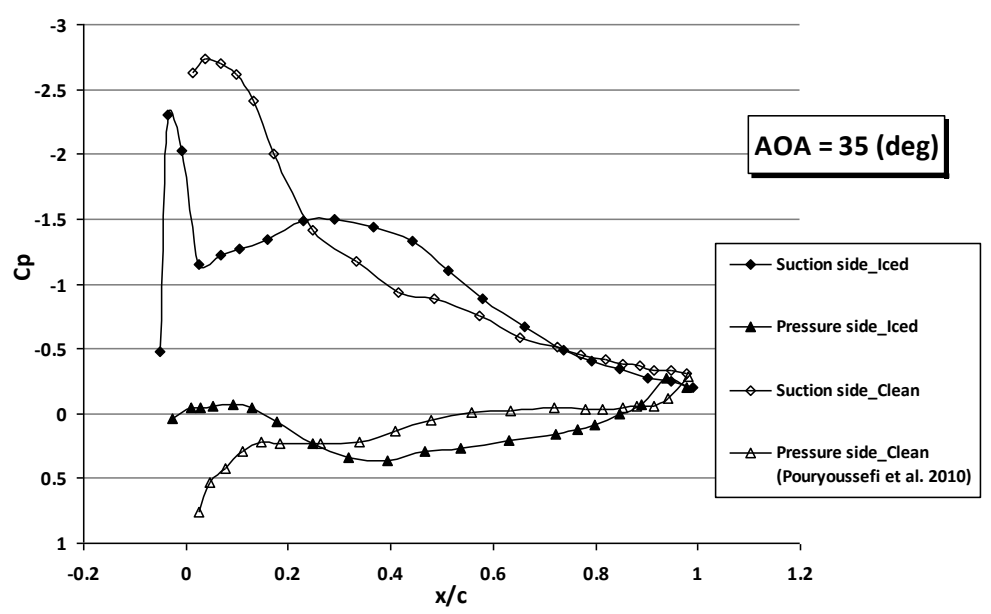

Fig. 9. The pressure coefficient distribution on the blade surface at $35^{\circ}$

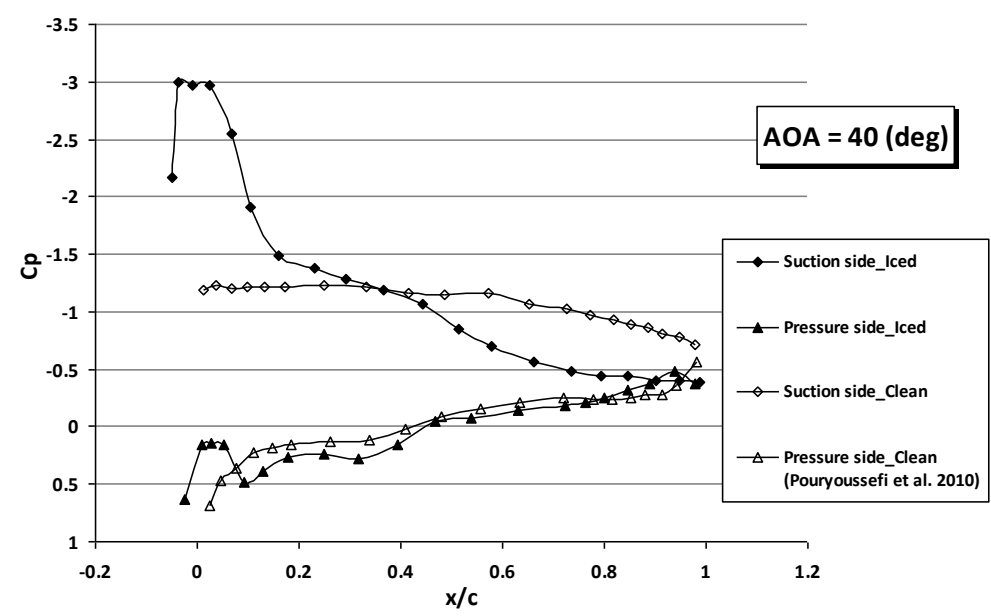

Fig. 10. The pressure coefficient distribution on the blade surface at $40^{\circ}$

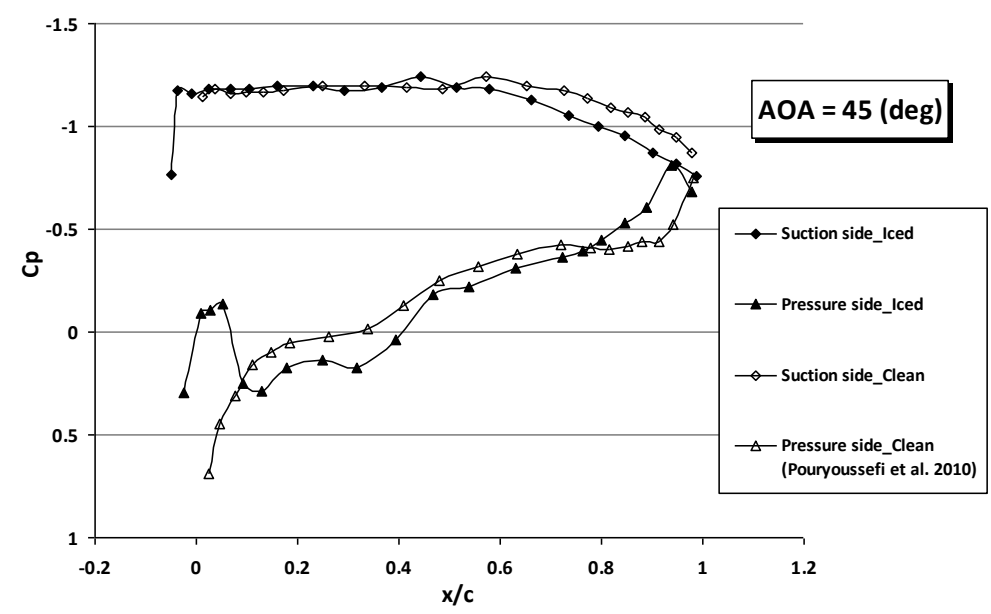

Fig. 11. The pressure coefficient distribution on the blade surface at $45^{\circ}$

$x / c \approx 0.45$ and then recovers. Comparing the clean blades at the same angle of attack, it is found that the diffusion point at the suction side in the iced blades has shifted toward the trailing edge. There is a negative constant pressure region at the pressure side from the leading edge to $x / c \approx 0.5$ which signify the separated bubbles downstream of the iced leading edge and then the pressure coefficient gradually increases. For $20^{\circ}$, the pressure distribution curve for the iced blade has shifted upward in comparison with that of the clean one, which expresses the iced blades experience less pressure. In $25^{\circ}$, due to the local suction at the suction side of the leading edge, a pick appears for the pressure 
curve at $x / c \approx 0.02$. While this pick for clean blades occurs in $30^{\circ}$; therefore ice accretion causes this pick to appear at lower angle and closer to the leading edge. After the pick, the pressure coefficient decreases up to $x / c \approx 0.45$ (diffusion point) and then increases. For this case, at the pressure side, the separated bubble length downstream the iced leading edge (which is recognized by constant pressure region) has decreased in comparison with $20^{\circ}$ for the iced blades and has extended from leading edge to about $x / c=0.4$. It is also evident that the pressure distribution is shifted upward comparing to the clean blades at the same angle of attack. The major trends for the pressure coefficient distribution in $30^{\circ}$ are quite similar to the distribution of $20^{\circ}$ and $25^{\circ}$ cases. For instance, the bubble length decreases in comparing with $25^{\circ}$ and has extended from the leading edge to $x / c \approx 0.2$. By increasing the angle of attack to $35^{\circ}$, a considerable difference appears between the pressure distribution of the clean blades and that of the iced blades. In this angle, the clean blades are close to the aerodynamic stall condition and the diffusion point has shifted toward the leading edge, the separation starts at the trailing edge at the suction side, whereas there is no unexpected phenomenon for the iced blades at this angle of attack. By increasing the angle of attack from $20^{\circ}$ to $35^{\circ}$, the separated bubble length decreases and the pressure coefficient increases, continuously. This can be due to the reduction of strength and size of the bubble vortices. In $40^{\circ}$, the pressure coefficient behavior for the iced blades significantly changes comparing to the lower angles due to approaching to stall condition. At the suction side on the iced blades in this angle of attack, the flow separation starts from the trailing edge up to $x / c \approx 0.7$. Moreover, there is no specific diffusion point for the iced blades in this angle. On the other hand, considering the positive sign of the pressure coefficients at the downstream of the iced leading edge at the pressure side, the flow bubble vanishes in $40^{\circ}$. Starting the separation at the suction side and increasing the angle of attack, cause the flow separation area to extend from the trailing edge to the leading edge, in $45^{\circ}$ for the iced blades. In this angle, whole the suction side is exposed to the separation. The pressure distributions for the clean and iced blades at the suction side are similar in $45^{\circ}$ due to the stall condition. To obtain more details about the separation extension at the suction side, more experiments are needed in the range of $40^{\circ}$ to $45^{\circ}$ for the iced blades. As pointed before, by increasing the angle of attack the effects of flow interference between the blades increase. Therefore, the pressure distributions at the pressure side in $40^{\circ}$ and $45^{\circ}$ comparing to the lower angles, experience different behavior.

The variation of lift coefficient vs. angle of attack is shown in Fig. 12. The difference between the clean and iced blades is negligible up to $35^{\circ}$. It is found that at this angle of attack range, the lift coefficient for iced blade is a little bit lower than that of the clean one. While in $40^{\circ}$ and $45^{\circ}$, the iced blades experience higher lift coefficient. Considering the lift coefficient, the clean blade stall occurs at lower angle of attack comparing to the iced blade, in fact icing delays the aerodynamic stall. This phenomenon is due to the blunt ice shape on the leading edge. Figure 13 shows the variation of drag coefficient vs. angle of attack. It can be seen that the drag coefficient of the iced blade is higher than that of the clean one from $20^{\circ}$ to $35^{\circ}$. However, for $40^{\circ}$ and $45^{\circ}$, the iced blade experiences lower drag coefficient. For iced blade just like the clean one, there is a decrease in the drag coefficient growth rate before stall (from $35^{\circ}$ to $40^{\circ}$ ). This specific behavior (which issues from the flow interference between the blades) appears for the cascaded blades, whereas for the single blade or airfoil, this coefficient and its growth rate continuously increase by increasing the angle of attack. Figure 14 shows that the moment coefficient for both iced and clean blades are approximately equal from $20^{\circ}$ to $30^{\circ}$ and decreases as the angle of attack increases. According to the leading edge moment coefficient for both clean and iced blades, these values experience little variations in the range of -0.3 to -0.4 .

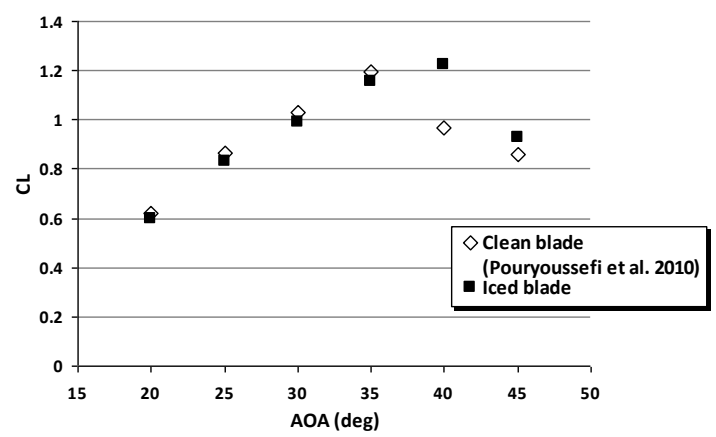

Fig. 12. The lift coefficient variation due to angle of attack changes

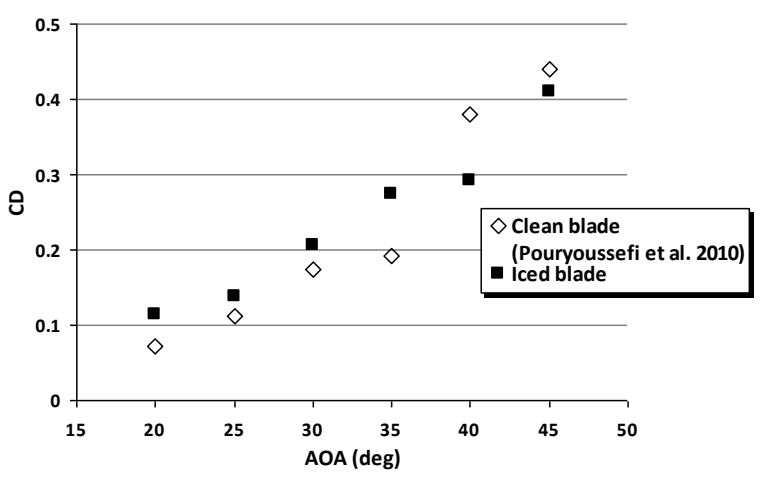

Fig. 13. The drag coefficient variation due to angle of attack changes 


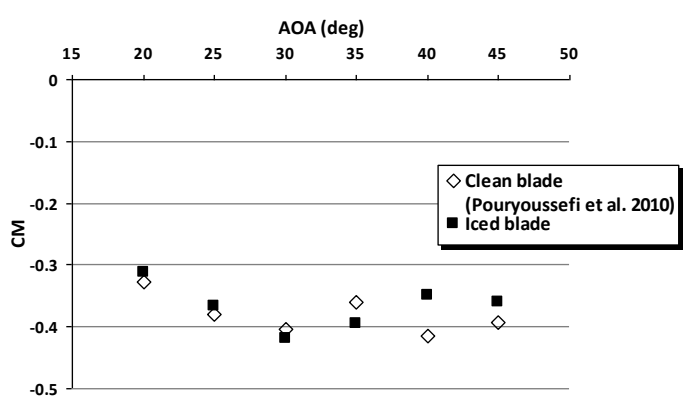

Fig. 14. The moment coefficient variation due to angle of attack changes

\section{CONCLUSION}

The effects of ice accretion on a 67A type blades cascade which are generally used in the first stator stage of turbofan compressors has been experimentally investigated. The wind tunnel tests were carried out to measure the pressure distribution and the aerodynamic coefficient on the iced blades for six different cascade angle of attack from $20^{\circ}$ to $45^{\circ}$ at Reynolds number of 500000 and the results were compared with those of the clean ones.

It is found that the angle of attack variations have significant effects on the flow pattern and the aerodynamic coefficients for the clean and iced blades and by increasing the angle of attack, the effects of the flow interference between the blades increase. Moreover, it is concluded that the ice accretion on the blades causes the separated bubble formation at the downstream of the leading edge on the pressure side. It is found that by increasing the angle of attack from $20^{\circ}$ to $35^{\circ}$, the separated bubble length decreases and corresponding pressure coefficient increases, constantly. In addition, due to the ice accretion, the diffusion point at the suction side shifts toward the trailing edge. The ice accretion effect on the lift coefficient up to $35^{\circ}$ is negligible but causes an increase in the drag coefficient comparing to the clean blades. By increasing the flow interference between the blades in $40^{\circ}$ and $45^{\circ}$, the iced blades experience higher lift coefficient and lower drag coefficient in comparison with the clean ones. On the other hand, increasing the angle of attack leads to initiate the flow separation at the suction side and extends the separation region towards the leading edge. The aerodynamic stall for the clean blades occurs in the range of $35^{\circ}$ to $40^{\circ}$ and for the iced blades, the stall takes place between $40^{\circ}$ to $45^{\circ}$. This delay in the blade's stall is due to the blunt ice shape on the leading edge of the blades.

Finally, it is suggested that for the analysis and better understanding of the aerodynamic behavior of the cascade of the stator blades, especially in attack angle close to aerodynamic stall (from $35^{\circ}$ to $45^{\circ}$ ) and also the effects of ice accretion, there should be comprehensive experimental and numerical researches.

\section{REFERENCES}

Jin, W. and R. Taghavi (2008). Computational Study of the Effects of Ice Accretions on the Flow Fields in the M2129 S-Duct Inlets, AIAA Paper 08-0075.

Lee, S., E. Loth, A. Broeren and M. Bragg (2006). Simulation of Icing on a Cascade of Stator Blades, AIAA Paper 06-208.

Lee, S. and E. Loth (2008). Simulation of Icing on a Cascade of Stator Blades, Journal of Propulsion and Power 24(6), 1309-1316.

Mason, J., W. Strapp and P. Chow (2006). The Ice Particle Threat to Engines in Flight, AIAA Paper 06-0206.

Mirzaei, M., M. A. Ardekani and M. Doosttalab (2009). Numerical and experimental study of flow field characteristics of an iced airfoil, Aerospace Science and Technology 13(6), 267-276.

Pouryoussefi, M. H., M. Mirzaei and M. Ramezanizadeh (2010). Experimental Investigation of Pressure Distribution and Aerodynamic Coefficients in a Blade Cascade of an Airplane Engine Compressor, Journal of Aeronautical Engineering 12(1), 1-10 (in Persian).

Rasmussen, R., C. Wade, F. Hage, S. Ladolt, M. Tryhane, J. Cole, A. Ramsay, D. Fleming, R. Moore, A. Davis, B. Reis, T. Lisi, M. Kjolleberg and K. Rosenlund (2006). Ingesting by Jet Engines, AIAA Journal 43(5), 1448-1457.

Sanger, N. L. (1983). The Use of Optimization Techniques to Design Controlled-Diffusion Compressor Blading, Journal of Engineering for Power 105, 256-264.

Sanger, N. L. and R. P. Shreeve (1986). Comparison of Calculated and Experimental Cascade Performance for Controlled-Diffusion Compressor Stator Blading, Journal of Turbomachinery 108, 42-50.

Venkataramani, K., L. McVey, R. Holm and K. Montgomery (2007). Inclement Weather Considerations for Aircraft Engines, AIAA Paper 07-0695. 